\title{
Stress and its effect on noncommunicable disease: An insight
}

\author{
Sankhadeep Ghosh, Komal Verma ${ }^{1}$
}

Amity School of Engineering and Technology, ${ }^{1}$ Amity Institute of Behavioural and Allied Sciences, Amity University, Rajasthan, India

\begin{abstract}
Stressors are an evident part of any individuals life and affects a lot of aspects of any individual. While the young generation or healthy individuals cope with it easily and favorably, however, the older people or unhealthy individuals are affected more adversely in case the stressors are persistent for a long time. This paper deals with providing an insight of the effect of stress on noncommunicable diseases.
\end{abstract}

Keywords: Disease, lifestyle, noncommunicable, stress

Address for correspondence: Komal Verma, Amity Institute of Behavioural and Allied Sciences, Amity University, Rajasthan, India.

E-mail: komalverma01@gmail.com

Received: 20.9.2017, Accepted: 28.10.2017

\section{INTRODUCTION}

The well-being of life is dependent on keeping our internal situation constant in today's changing environment. ${ }^{[1]}$ This perception was termed as "homeostasis." ${ }^{[2]}$ In 1956, ${ }^{[3]}$ Selye used the term "stress" to represent anything that seriously threatens this homeostasis. The actual or perceived threat to any organism is referred to as the "stressor" and the response to it is called the "stress response." Although stress responses progressed as adaptive processes, Selye observed that severe, prolonged responses might lead to adverse effects in the form of diseases.

On the basis of the apparent threat, humans and other animals incorporate coping responses. ${ }^{[4]}$ Thus, when fight or flight becomes feasible, mammals exhibit increased autonomic and hormonal activities that enhance muscular exertion. ${ }^{[2,5]}$ In contrast, during avoiding situations in which a coping response is not viable, mammals may show a response that involves the sympathetic nervous system (SNS) arousal accompanied by an active inhibition of movement. ${ }^{[6]}$ Lacey, in 1967, ${ }^{[7]}$

\begin{tabular}{|l|l|}
\hline \multicolumn{2}{|c|}{ Access this article online } \\
\hline Quick Response Code: & Website: \\
\cline { 1 - 2 } & www.joshd.net \\
\cline { 2 - 2 } & DOI: \\
& 10.4103/joshd.J_Soc_Health_ \\
\hline Diabetes_32_17
\end{tabular}

gave the term "situational stereotypy," which can be defined as the extent to which various situations exhibit various biological reactions.

Nevertheless, there are also person-to-person differences in stress responses to exactly the similar situation. Across a variety of situations, some individuals tackle stress with active coping, whereas others exhibit aversive vigilance. ${ }^{[8]}$

Although genetic inheritance is the main cause in determining discrete differences in response stereotypy, neonatal experiences in rats have been proved to have long-term effects on cognitive-emotional responses. ${ }^{[9]}$ For example, it was studied by Meaney et al. in $1993^{[10]}$ that rats raised by nurturing mothers have more levels of central serotonin activity compared with those brought up by less fostering mothers. The increased serotonin leads to increased presence of a central glucocorticoid receptor gene. This leads to more numbers of glucocorticoid receptors

This is an open access journal, and articles are distributed under the terms of the Creative Commons Attribution-NonCommercial-ShareAlike 4.0 License, which allows others to remix, tweak, and build upon the work non-commercially, as long as appropriate credit is given and the new creations are licensed under the identical terms.

For reprints contact: reprints@medknow.com

How to cite this article: Ghosh S, Verma K. Stress and its effect on noncommunicable disease: An insight. J Soc Health Diabetes 2018;6:15-21. 
and improved glucocorticoid feedback throughout the rat's life cycle. Surprisingly, female rats who experience more nurturing also become more nurturing ones, and thus, their progeny have high levels of glucocorticoid receptors. This example portrays that highly nurtured rats transform into low-anxiety adults, who eventually become nurturing mothers with less stress reactions.

Ladd et al. in $2000^{[11]}$ studied that pups that were separated from their mothers for many hours each day during initial life have a highly energetic hypothalamic-pituitaryadrenocortical axis and elevated SNS arousal. These deprived animals show larger and more frequent stress responses to the environment than do less deprived ones.

As mammals have evolved with rationally effective homeostatic mechanisms for coping with various short-term stressors, acute stress responses in young individuals typically do not cause much of a health burden. However, if the threat is persistent for quite some duration, specifically in different older and unhealthy individuals, the long-term effects of the stress response may affect health. ${ }^{[12]}$ Adverse effects of chronic stressors are very much common in humans, which maybe because of their increased capacity for thought that may give rise to persistent stress responses to a wide range of adverse conditions. The relationship between stressors and chronic disease is somewhat intricate. It is affected by the nature, number, and persistence of the stressors as well as by one's biological vulnerability and known patterns of coping. In this review, we assess some effects of specific stressors in various areas, the interceding psychophysiological pathways, and the variables to facilitate these relationships.

\section{COMMON CHILDHOOD AND ADOLESCENCE STRESSORS}

The most-studied stressors in children and adolescents are violence, various types of abuse (sexual, physical, emotional, or neglect), and divorce/marital issues. ${ }^{[13]} \mathrm{Few}$ of the psychological effects of maltreatment/abuse are the dysregulation of affect, provoking behaviors, the evasion of intimacy, and turbulences in attachment. ${ }^{[14]}$ Childhood sexual abuse survivors have more levels of both general distress and major psychological disturbances, which also include personality disorders. ${ }^{[15]}$ Abuse during the early stages of life is also related to the negative approaches toward learning and poor performance in academics. ${ }^{[16]}$ Children of divorced parents have greater inclination toward antisocial behaviors, anxiety, and depression than their peers, which has been significantly reported over the years. ${ }^{[17]}$ During the adult stage, the wards of divorced parents report more life stress, family conflicts, and lack of friendly support compared with those whose parents are still together. ${ }^{[17]}$ Introduction to nonresponsive settings has also been defined as a stressor leading to learned powerlessness. ${ }^{[18]}$

Over the years, studies have also shown the psychological effects of exposure to war and terrorism during childhood days. ${ }^{[19]}$ A majority of children exposed to the war scenario have been reported to have significant psychological morbidity, including both post-traumatic stress disorder (PTSD) and depressive symptoms. For example, in 1993, Nader et al. ${ }^{[20]}$ studied and inferred that $70 \%$ Kuwaiti children reported mild-to-severe PTSD symptoms after the Gulf War. Some effects do last for a significantly longer time; in 1996, Macksound and $A b e r^{[21]}$ had concluded that $43 \%$ Lebanese children continued to manifest PTSD symptoms even after 10 years of exposure to war-related trauma.

Exposure to powerful and long-lasting stressors during the developmental years has long-lasting neurobiological effects and puts one at amplified risks for anxiety and mood disorders, aggressive dyscontrol problems, hypoimmune dysfunction, medical morbidity, structural changes in the CNS, early death, and so on. ${ }^{[19]}$

\section{COMMON STRESSORS IN ADULT STAGE AND THEIR EFFECT ON ANXIETY AND DEPRESSION}

It is known that first depressive episodes often show up following the happening of a major negative life event. ${ }^{[22]}$ Furthermore, there is enough evidence to show that stressful life events are very common for the occurrence of depression. ${ }^{[23]}$ A study of 13,006 patients in Denmark, with first psychiatric admissions detected with depression, were found to be affected more by recent divorces, unemployment, and suicides by fellow relatives when compared to age- and gender-matched controls. ${ }^{[2]}$ The diagnosis of any sort of medical illness often has been termed and evaluated as a severe life stressor and frequently is accompanied by high rates of depression. ${ }^{\text {[25] }}$ For example, a detailed analysis showed that $24 \%$ of patients with cancer are diagnosed with major depression episodes. ${ }^{[26]}$

Stressful life events often take place before most anxiety disorders. ${ }^{[27,28]}$ Interestingly, long-term studies have shown that anxiety sets in more usually before depression. ${ }^{[29,30]}$ In fact, in potential studies, patients with anxiety have been seen to have high chances of developing major depression symptoms after stressful life events. ${ }^{[31]}$ 


\section{TRAUMATIC DISORDERS}

Lifetime exposure to traumatic events among the common people is alarmingly high, with estimates varying from $40 \%$ to $70 \%{ }^{[32]}$ It is to be noted that an estimated $13 \%$ adult women in the United States have been exposed to sexual assault in some way or the other. ${ }^{[33]}$ The Diagnostic and Statistical Manual of Mental Disorders names two primary diagnosis related to trauma: acute stress disorder (ASD) and PTSD. ${ }^{[34]}$ The noticeable features of these are traumatic events involving actual or threatened death or serious injury and other symptoms that include reexperiencing that particular traumatic event, avoidance of reminders, and hyperarousal resulting in difficulty in falling or staying asleep. The time duration for ASD is shorter (lasting 2 days to 4 weeks), with diagnosis taking place at maximum within 1 month of the incident. The term ASD was familiarized in 1994 to describe initial traumatic reactions, but it has been highly criticized ${ }^{[35]}$ for the frail observed and theoretical support. Most people who exhibit PTSD symptoms shortly after a traumatic event recover soon and do not develop PTSD. In an extensive review, in 1994, Green ${ }^{[36]}$ estimated that around $25 \%$ of those exposed to traumatic events develop PTSD. Surveys have indicated that PTSD affects 1 in 12 adults at some time or the other in their life. ${ }^{[37]}$ Trauma and disasters are connected not only to PTSD, but they also involve a number of effects that include concurrent depression, other different anxiety disorders, thinking impairment, and substance abuse. ${ }^{[38-40]}$

Other ill effects of stress that could provide adverse impacts on health have been identified, such as increase in the frequency of smoking, substance abuse, accidents, insomnia problems, and disorders in the food habits. Those who live in highly stressed environments (which means with higher divorce rates, business failures, natural disasters, etc.) smoke more severely and experience high death rate from lung cancer and chronic obstructive pulmonary disorder. ${ }^{[41]} \mathrm{A}$ surprising revelation was made following seamen in a naval training center were found to smoke more on high-stress days. ${ }^{[42]}$ Stress occurring out of one's life events and persistent stressful conditions have also been matched to higher consumption of alcohol. ${ }^{[43]}$ Further, it was also held that there was a possibility that alcohol may be used as self-medication for stress-related disorders such as anxiety. For example, a community study of 3021 adolescents and young adults ${ }^{[4]}$ found that those having anxiety disorders were more probable to take up substance abuse or dependence prospectively. Sustaining life in severe stressful conditions has also been interrelated to fatal accidents ${ }^{[45]}$ and to the initiation of bulimia. ${ }^{[4]}$ Another prominent factor related to stress that could affect health is the problem related to sleep that has been observed after psychological trauma. ${ }^{[4]}$ Commencement of sleep problems enabled the relationship between PTSD symptoms and reduced natural killer (NK) cell cytotoxicity in Hurricane Andrew victims. ${ }^{[48]}$

\section{ACUTE STRESS RESPONSES}

A lot of changes occur in the nervous, cardiovascular, endocrine, and immune systems after any stressful event. They constitute the type of stress response and are generally adaptive as per Selye (1956). ${ }^{[3]}$ Two features make the stress response adaptive, i.e., stress hormones are released and a new pattern of energy distribution evolves. Less serious activities of the body are suspended.

Cardiac responses are believed to enable active coping by forcing blood to the skeletal muscles, steady with the fight-or-flight response. The vascular mechanism of response thrusts blood away from the edge to the internal organs, thereby reducing bleeding in situations of physical assault.

\section{CHRONIC STRESS RESPONSES}

Selye in his work also talks about how acute stress response mechanism can become problematic if it is repeatedly activated. Over a significant period, the recurrently elevated and quickly unstable levels of blood pressure can lead to severely damaged arteries and plaque occurrence.

In reaction to more chronic stressors, Segerstrom and Miller ${ }^{[49]}$ concluded that proinflammatory, Th1 and Th2, cytokines become dysregulated and give way to both suppressed humoral and cellular immunity. Chronic stressors are accompanied by slower wound healing and recovery from surgery, poorer antibody responses, and antiviral shortages that contribute to increased exposure to viral infections. Chronic stress is specifically problematic for elderly people in terms of immune senescence, which is the gradual loss of immune function associated with aging. ${ }^{[50]}$

\section{VARIOUS STRESS-CAUSING FACTORS AND THEIR EFFECT ON DISEASES}

\section{Cardiovascular disease}

Relationships between psychosocial stressors and disease have been extensively reported in several studies. It was found that men with relatively low socioeconomic status are at risk of being affected by coronary heart disease (CHD) $\cdot{ }^{[51]}$ Much of the risk regarding CHD can be removed by considering the lack of perceived job control, which is a powerful stressor. ${ }^{[52]}$ Other causes include behaviors such as smoking, alcohol consumption, and sedentary lifestyle, 
which have high chances to be effects of stress. ${ }^{[53]}$ Work stress has been reported to be an important cause of incident CHD and hypertension. ${ }^{[54]}$ However, in women who already have $\mathrm{CHD}$, marital stress precedes work stress as a better predictor of poor forecast. ${ }^{[5]}$

Although observational studies have always portrayed challenging links between psychosocial stressors and diseases, they are limited to the accurate contribution of these stressors or about how stress promotes various diseases. Animal models have been extensively used to understand the specific influences of stressors on various stress-related diseases. This is especially true of atherosclerotic CHD, which takes a long time, maybe decades, to develop in humans. It is absolutely unethical to induce disease in humans by experimentation.

The major findings from the study of animal models were that (1) socially prevailing animals living in unstable groups had expressively more atherosclerosis and (2) socially prevailing male animals living in unstable groups had significantly more atherosclerosis. ${ }^{[5]}$ However, subsidiary premenstrual females grow greater atherosclerosis than dominant females. ${ }^{[57]}$ The studies on cynomolgus monkeys indicate that emotionally stressful behavior can quicken the evolution of atherosclerosis.

\section{Upper respiratory diseases}

The famous hypothesis that stress often forecasts vulnerability to the common cold received a great support from the observations that were made or observational studies. ${ }^{[58,59]}$ However, these studies do not control for exposure. People who undergo a lot of stress often seek to spend time outside a confined place or atmosphere and hence, they have the vulnerability of getting exposed to more viruses. Therefore, in a more controlled way, people were exposed to a rhinovirus and thereafter confined to control the exposure to several other viruses. ${ }^{[60]}$ Individuals with the most stressful events in their life and uppermost levels of apparent stress and negative affect had the utmost chance of having cold symptoms. In a subsequent study wherein volunteers were vaccinated with a cold virus, it was seen that people sustaining any sort of chronic, stressful life events had a high possibility of catching cold, whereas those who had stressful incidents in their life for less than a month had extremely less chances of catching it. ${ }^{[61]}$

\section{Human immunodeficiency virus}

The impact of life stressors on human immunodeficiency virus (HIV) spectrum disease has also been extensively studied upon. Leserman et al. in 2000 $0^{[2]}$ observed men with HIV for as long as 7.5 years and concluded that faster advancement of AIDS was associated with the following: growing stressful life events, denial strategy that was used as a coping mechanism, very less satisfaction in terms of social support, and raised serum cortisol.

\section{Diabetes}

In people with diabetes, the fight-or-flight situation does not respond effectively. When under mental stress, individuals with type 2 diabetes generally experience an increase in blood sugar levels whereas those with type 1 diabetes can experience either an increase or a decrease in the blood glucose levels. When under physical stress, the blood sugar levels may increase and this can affect both types of patients with diabetes. The elevation in the blood sugar levels is mainly due to two reasons. First, the stress hormones increase the blood glucose levels to a considerable level. Second, individuals who are experiencing stress generally forget to look after the health in a proper manner. Chronic stress can also increase the complications related to diabetes.

\section{STRESS AND ITS EFFECT ON INFLAMMATORY CONDITIONS AND IMMUNE SYSTEM}

Stress has also been linked with worsening of autoimmune disease $^{[63]}$ and other allied conditions wherein excessive inflammation is a key feature, such as CHD. ${ }^{[64]}$ Evidence proposes that a chronically stimulated, dysregulated acute stress response is the key reason for such linkages. We know that the acute stress response encompasses the activation and migration of cells of the inborn immune system. This is facilitated by proinflammatory cytokines. During times of chronic stress, cortisol suppresses proinflammatory cytokine production, but in people with autoimmune disease or $\mathrm{CHD}$, prolonged stress leads to proinflammatory cytokine production, which in turn gives way to worsening of pathophysiology and symptomatology.

As cortisol fails to suppress inflammation, stress promotes proinflammatory cytokine production for indefinite time. ${ }^{[65]}$ In rheumatoid arthritis, excessive swelling is the main cause for joint damage, swelling, accompanied pain, and reduced mobility. Stress is linked with apparent pronounced swelling and reduced agility in patients with rheumatoid arthritis. ${ }^{[6]}$ In the same manner, in multiple sclerosis (MS), an overexcited immune system targets and destroys the myelin nearby the nerves, causing adverse effects that may include paralysis and blindness. Again, stress is associated with a negative acceleration of disease. ${ }^{[6]}$ Even in CHD, inflammation exhibits a vital role. Higher levels of inflammatory markers are predictive of heart attacks, even when other traditional reasons are controlled. ${ }^{\left[{ }^{[8]}\right]}$ There is a strange history of major depressive episodes in men with increased levels of C-Reactive Protein (CRP). ${ }^{[69]}$ 


\section{STRESS AND ITS EFFECT ON MENTAL HEALTH}

Sustained proinflammatory cytokine production may also adversely affect mental health in susceptible individuals. During times of illness, proinflammatory cytokines can produce symptoms of fatigue, malaise, diminished appetite, and restlessness, which are symptoms usually associated with depression. It was previously assumed that these symptoms were directly produced by infectious pathogens, but in recent times, it has been clearly stated that proinflammatory cytokines are both sufficient and necessary to cause sickness behavior. ${ }^{[70,71]}$

Sickness behavior has been concluded as a highly ordered strategy that mammals use to fight infection. ${ }^{[69]}$ Sickness behavior is also thought to promote resistance and enable recovery. An overall decrease in normal activity allows the sick person to preserve energy resources that can be utilized toward enhancing immune activity. Similarly, limiting other related activities further conserve energy resources and reduce the probability of risky encounters. Furthermore, with the decrease in food intake, the level of iron in the blood also considerably reduces, thereby lessening bacterial replication. Thus, for a short period, sickness behavior can be coined as an adaptive response to the stress of illness.

Sickness behavior can become maladaptive when recurrently activated. Many essential features of the sickness behavior reaction overlap with major depression. Indeed high rates of depression are reported in patients with inflammatory diseases. ${ }^{[67,72]}$ Patients with MS do face many stressors and complaints of depression are normal. However, when compared with individuals facing the same scenario but who do not have MS, patients with MS still have comparatively higher levels of depression. ${ }^{[73]}$ In both $\mathrm{MS}^{[74]}$ and $\mathrm{CHD}{ }^{[69]}$ indicators of inflammation have been closely connected with depressive symptoms. Thus, there is enough proof to suggest that stress gives rise to both physical and mental diseases through the intermediating properties of proinflammatory cytokines.

\section{CONCLUSTION}

Humans as well as all living beings face the challenge of maintaining the internal situation constant with the changing environment and the prospect is governed by the capability to adapt to any category of stress. ${ }^{[75]}$ Stress can lead to diseases in people with poor adapting nature, which is quite evidently highlighted in this article. It was highlighted how stressors affect both mental and physical health. Stress is a part and parcel of our life and the way we deal with it shall always govern further health implications.
Financial support and sponsorship Nil.

\section{Conflicts of interest}

There are no conflicts of interest.

\section{REFERENCES}

1. Bernard C. Introduction to the study of experimental medicine. Greene HC, trans. New York: Collier; 1961 [1865].

2. Cannon WB. Bodily changes in pain, hunger, fear and rage. 2 nd ed. New York: Appleton; 1929.

3. Selye H. The stress of life. New York: McGraw-Hill; 1956.

4. Lazarus RS, Folkman S. Stress, appraisal and coping. New York: Springer; 1984.

5. Hess WR. Functional organization of the diencephalons. New York: Grune \& Stratton; 1957.

6. Adams DB, Baccelli G, Mancia G, Zanchetti A. Cardiovascular changes during naturally elicited fighting behavior in the cat. Am J Physiol 1968;216:1226-35.

7. Lacey JI. Somatic response patterning and stress: Some revisions of activation theory. In: Appleyo MH, Trumble R, editors. Psychological stress. New York: Appleton-Century-Crofts; 1967. p 14.

8. Kasprowicz AL, Manuck SB, Malkoff SB, Krantz DS. Individual differences in behaviorally evoked cardiovascular response: Temporal stability and hemodynamic patterning. Psychophysiology 1990;27:605-19.

9. Levine S. Infantile experience and resistance to physiological stress. Science 1957;126:405-6.

10. Meaney MJ, Bhatnagan S, Dioria J, Larogue S, Francis D, O’Donnell D, et al. Molecular basis for the development of individual differences in the hypothalamic-pituitary-adrenal stress response. Cell Mol Neurobiol 1993;13:321-47.

11. Ladd CO, Huot RL, Thrivikraman P, Nemeroff CB, Meaney MJ, Plotsky PM. Long-term behavioral and neuroendocrine adaptations to adverse early experience. Prog Brain Res 2000;122:79-101.

12. Schneiderman N. Pathophysiology in animals. In: Dembroski TM, Schmidt TH, Blümhen G, editors. Biobehavioral bases of coronary heart disease. Basel: Karger; 1983. pp304-64.

13. Cicchetti D. Child maltreatment. Annu Rev Clin Psychol 2005;1: 409-38.

14. Haviland MG, Sonne JL, Woods LR. Beyond posttraumatic stress disorder: Object relations and reality testing disturbances in physically and sexually abused adolescents. J Am Acad Child Adolesc Psychiatry 1995;34:1054-9.

15. Lowenthal B. The effects of early childhood abuse and the development of resiliency. Early Child Dev Care 1998;142:43-52.

16. Short JL. The effects of parental divorce during childhood on college students. J Divorce Remarriage 2002;38:143-56.

17. Peterson C, Seligman MEP. Causal explanations as a risk factor for depression: Theory and evidence. Psychol Rev 1984;91:347-74.

18. Shaw JA. Children exposed to war/terrorism. Clin Child Fam Psychol Rev 2003;6:237-46.

19. Paykel ES. Stress and affective disorders in humans. Semin Clin Neuropsychiatry 2001;6:4-11.

20. Nader KO, Pynoos RS, Fairbanks LA, al Ajeel M, al-Asfour A. A preliminary study of PTSD and grief among the children of Kuwait following the Gulf crisis. Br J Clin Psychol 1993;32:407-16.

21. Macksound M, Aber J. The war experience and psychosocial development of children in Lebanon. Child Dev 1996;67:70-88.

22. Hammen C. Stress and depression. Annu Rev Clin Psychol 2005;1:293-319.

23. Kessing LV, Agerbro E, Mortensen PB. Does the impact of major stressful life events on the risk of developing depression change throughout life? Psychol Med 2003;33:1177-84.

24. Cassem EH. Depressive disorders in the medically ill: An overview. Psychosomatics 1995;36:S2-S10. 
25. McDaniel JS, Musselman DL, Porter MR, Reed DA, Nemeroff CB. Depression in patients with cancer. Diagnosis biology and treatment. Arch Gen Psychiatry 1995;2:89-99.

26. Faravelli C, Pallanti S. Recent life events and panic disorder. Am J Psychiatry 1989;146:622-6.

27. Finlay-Jones R, Brown GW. Types of stressful life events and the onset of anxiety and depressive disorders. Psychol Med 1981;11:803-15.

28. Angst J, Vollrath M. The natural history of anxiety disorders. Acta Psychiatr Scand 1991;84:446-52.

29. Breslau N, Davis GC, Andreski P, Peterson E. Sex differences in depression: A role for preexisting anxiety. Psychiatr Res 1995;58:1-12.

30. Brown GW, Bifulco A, Harris T, Bridge L. Life stress, chronic subclinical symptoms and vulnerability to clinical depression. J Affect Disord 1986;11:1-19.

31. Norris FH. Epidemiology of trauma: Frequency and impact of different potentially traumatic events on different demographic groups. J Consult Clin Psychol 1992;60:409-18.

32. Kilpatrick DG, Edmunds CN, Seymour AK. Rape in America: A report to the nation. Arlington, VA: National Victims Center; 1992.

33. Harvey AG, Bryant RA. Acute stress disorder: A synthesis and critique. Psychol Bull 2002;128:886-902.

34. American Psychiatric Association. Diagnostic and Statistical Manual of Mental Disorders IV-TR. 4th ed. Washington, DC: American Psychiatric Association; 2000.

35. Kessler RC, Sonnega A, Bromet E, Hughes M, Nelson CB. Posttraumatic stress disorder in the National Comorbidity Survey. Arch Gen Psychiatry 1995;52:1048-60.

36. Green BL. Psychosocial research in traumatic stress: An update. J Trauma Stress 1994;7:341-62.

37. David D, Mellman TA, Mendoza LM, Kulick-Bell R, Ironson G, Schneiderman N. Psychiatric morbidity following Hurricane Andrew. Int Soc Trauma Stress Stud 1996;9:607-12.

38. Schnurr PP, Friedman J, Bernardy NC. Research on posttraumatic stress disorder: Epidemiology, pathophysiology and assessment. Psychother Pract 2002;58:877-89.

39. Shalev AY. What is posttraumatic stress disorder? J Clin Psychiatry 2001;62:4-10.

40. Colby JP, Linsky AS, Straus MA. Social stress and state-to-state differences in smoking-related mortality in the United States. Soc Sci Med 1994;38:373-81.

41. Conway TL, Vickers RR, Ward HW, Rahe RH. Occupational stress and variation in cigarette, coffee and alcohol consumption. J Health Soc Behav 1981;22:156-65.

42. Linsky AS, Strauss MA, Colby JP. Stressful events, stressful conditions, and alcohol problems in the United States: A partial test of the Bales theory of alcoholism. J Stud Alcohol 1985;46:72-80.

43. Zimmerman P, Wittchen HU, Hofler M, Pfister H, Kessler RC, Lieb R. Primary anxiety disorders and the development of subsequent alcohol use disorders: A 4-year community study of adolescents and young adults Psychol Med 2003;33:1211-22.

44. Linsky AS, Strauss M. Social stress in the United States: Links to regional patterns in crime and illness. Dover, MA: Auburn House; 1986.

45. Welch SL, Doll HA, Fairburn CG. Life events and the onset of bulimia nervosa: A controlled study. Psychol Med 1997;27:515-22.

46. Harvey AG, Jones C, Schmidt DA. Sleep and posttraumatic stress disorder: A review. Clin Psychol Rev 2003;23:377-407.

47. Ironson GH, Wynings C, Schneiderman N, Baum A, Rodriguez M, Greenwood D, et al. Posttraumatic stress symptoms, intrusive thoughts, loss, and immune function after Hurricane Andrew. Psychosom Med 1997;59:128-41.

48. Ferguson RG, Wikby A, Maxson P, Olsson J, Johansson B. Immune parameters in a longitudinal study of a very old population of Swedish people: A comparison between survivors and nonsurvivors. J Gerontol 1995;50:B378-B382.
49. Segerstrom SC, Miller GE. Psychological stress and the human immune system: A meta-analysis of 30 years of inquiry. Psychol Bull 2004;130:601-30

50. Marmot M. Social resources and health. In: Kessel F, Rosenfield PL, Anderson NB, editors. Expanding the boundaries of health and social science. New York: Oxford University Press; 2003. pp 259-85.

51. Marmot MG, Bosma H, Hemingway H, Brunner EJ, Stansfeld S. Contribution of job control and other risk factors to social variations in coronary heart disease incidence. Lancet 1997;350:235-9.

52. Lantz PM, House JS, Lepkowski JM, Williams DR, Mero RP, Chen J. Socioeconomic factors, health behaviors, and mortality: Results from nationally representative prospective study of US adults. JAMA 1998;279:1703-8

53. Ironson GH. Job stress and health. In: Cranny CJ, Smith PC, Stone EF, editors. Job satisfaction: How people feel about their jobs and how it affects their performance. New York: Lexington; 1992. pp 219-39.

54. Orth-Gomér K, Wamala SP, Horsten M, Schenk-Gustafsson K, Schneiderman N, Mittleman MA. Marital stress worsens prognosis in women with coronary heart disease. JAMA 2000;284: 3008-14.

55. Kaplan JR, Manuck SB, Clarkson TB, Lusso FM, Taub DM. Social status, environment and atherosclerosis in cynomolgus monkeys. Arteriosclerosis 1982;2:359-68.

56. Kaplan JR, Adams MR, Clarkson TB, Koritnik DR. Psychosocial influences on female "protection" among cynomolgues macaques. Atherosclerosis 1984;53:283-95.

57. Graham NMH, Douglas RB, Ryan P. Stress and acute respiratory infection. Am J Epidemiol 1986;124:389-401.

58. Meyer RJ, Haggerty RJ. Streptococcal infection in families. Pediatrics 1962;29:539-49.

59. Cohen S, Tyrrell DA, Smith AP. Psychological stress and susceptibility to the common cold. N Engl J Med 1991;325:606-12.

60. Cohen S, Frank E, Doyle WJ, Skoner DP, Rabin BS, Gwaltney JM, Jr. Types of stressors that increase susceptibility to the common cold in healthy adults. Health Psychol 1998;17:214-23.

61. Harbuz MS, Chover-Gonzalez AJ, Jessop DS. Hypothalamo-pituitaryadrenal axis and chronic immune activation. Ann NY Acad Sci 2003;992:99-106.

62. Leserman J, Pettito JM, Golden RN, Gaynes BN, Gu H, Perkins DO. The impact of stressful life events, depression, social support, coping and cortisol on progression to AIDS. Am J Psychiatry 2000;57:1221-8.

63. Appels A, Bar FW, Bar J, Bruggeman C, de Bates M. Inflammation, depressive symptomatology, and coronary artery disease. Psychosom Med 2000;62:601-5.

64. Miller GE, Cohen S, Ritchey AK. Chronic psychological stress and regulation of pro-inflammatory cytokines: A glucocorticoid-resistance model. Health Psychol 2002;21:531-41.

65. Affleck G, Urrows S, Tennen H, Higgins P, Pav D, Aloisi R. A dual pathway model of daily stressor effects on rheumatoid arthritis. Ann Behav Med 1997;19:161-70.

66. Mohr DC, Hart SL, Julian L, Cox D, Pelletier D. Association between stressful life events and exacerbation in multiple sclerosis: A meta-analysis. Br Med J 2004;328:731

67. Morrow DA, Ridker PM. C-reactive protein, inflammation, and coronary disease. Med Clin North Am 2000;81:149-61.

68. Danner M, Kasl SV, Abramson JL, Vaccarion V. Association between depression and elevated C-reactive protein. Psychosom Med 2003;65:347-56.

69. Dantzer R. Cytokine-induced sickness behavior: Where do we stand? Brain Behav Immun 2001;15:7-24.

70. Dantzer R. Cytokine, Sickness Behavior, and Depression. Neurologic Clinics 2006;24:441-60. doi:10.1016/j.ncl.2006.03.003. 
71. Larson SJ, Dunn AJ. Behavioral effects of cytokines. Brain Behav Immun 2001;15:371-87.

72. Carney RM, Rich MW, Tevelde A, Saini J, Clark K, Jaffe AS. Major depressive disorder in coronary artery disease. Am J Cardiol 1987;60:1273-5.

73. Ron M, Logsdail S. Psychiatric morbidity in multiple sclerosis: A clinical and MRI study. Psychol Med 1989;19:887-95.
74. Fassbender K, Schmidt R, Mössner R, Kischka U, Kühnen J, Schwartz A, et al. Mood disorders and dysfunction of the hypothalamic-pituitary-adrenal axis in multiple sclerosis: Associations with cerebral inflammation. Arch Neurol 1998;55:66-72.

75. Schneiderman N, Ironson G, Siegel SD. Stress and health: Psychological, behavioral and biological determinants. Annu Rev Clin Psychol, 2005;1:607-28. 